\title{
An Experience in Modelling Business Process Architecture
}

\author{
Geert Poels ${ }^{1[0000-0001-9247-6150]}$, Francisco Ruiz ${ }^{2[0000-0002-4923-7848]}$ and Félix García ${ }^{2[0000-}$ \\ 0001-6460-0353] \\ ${ }^{1}$ Faculty of Economics and Business Administration, Ghent University, Belgium \\ geert.poels@ugent. be \\ ${ }^{2}$ Institute of Information Technology and Systems, University of Castilla-La Mancha, Spain \\ \{felix.garcia, francisco.ruizg\}@uclm.es
}

\begin{abstract}
We present a mapping of a previously designed Business Process Architecture (BPA) meta-model onto ArchiMate, i.e., the de facto standard Enterprise Architecture (EA) modelling language. This construct mapping allows developing process maps, i.e., descriptions of (views of) the business process architecture of an organization. We demonstrate the development of these process maps using the Signavio Business Process Management (BPM) modelling platform. The developed process maps are part of the organization's enterprise architecture model and are linked to BPMN process diagrams that detail the functional, control-flow, data and resource aspects of the business processes included in the process map. Our research contributes to the integration of BPM and EA by researching BPA as a concept common to both disciplines.
\end{abstract}

Keywords: Process map, Business process architecture, Enterprise architecture.

\section{$1 \quad$ Introduction}

In the Business Process Management (BPM) field, quality is one of four business process performance dimensions, collectively known as the Devil's Quadrangle (i.e., time, cost, quality, flexibility) [1]. Process quality can be internal or external [1], where the former refers to the process participants' perspective (e.g., job satisfaction) and the latter to the process clients' perspective (e.g., satisfaction with the process outcome). Bearing on insights from software quality [2], we contend that fit for purpose is another quality viewpoint. This type of quality hasn't received much attention in BPM. In the context of business processes, we see fit for purpose as the fit between an organization's competitive positioning and its internal arrangement [3]. In this perspective, quality of business processes refers to how effective these processes are in implementing an organization's chosen strategy (i.e., strategic alignment). Unlike the other two quality perspectives, this quality dimension cannot be assessed for isolated processes. It requires a holistic view of an organization's collection of business processes as the raison d'être of a process depends on its role in the business (process) architecture of an organization. 
The question of fit for purpose of an organization's business processes is addressed in the field of Enterprise Architecture (EA). Like many BPM quality evaluation and improvement techniques [4], [5], [6], many EA analysis techniques are model-based, i.e., require a model of the artefact to be analyzed. For instance, the Process-GoalAlignment (PGA) method for strategic alignment analysis [7] requires a model of the business architecture representing value chains, their activities, and their relationships with organizational goals and components of the business model.

Models of business process architecture are referred to as process maps [8] or process landscape models [1]. To analyze the fit for purpose of an organization's business processes, the following requirements must be met:

- Being able to systematically develop process maps that represent an organization's collection of business processes;

- Being able to integrate process maps into enterprise architecture models.

Currently, there does not exist a generally used language for modelling business process architectures that allows for integration of process maps into enterprise architecture models. Recently, Malinova [9] designed a modelling language for process maps, based on extensive empirical research into the most commonly used concepts and symbols for representing business process architectures. A related proposal for modelling process landscapes and value chains of core processes is included in the most recent version of the BPM textbook Fundamentals of Business Process Management [1]. These proposals did not address how to integrate the models into enterprise architecture models. To address this gap, we initiated a research project developing a tool-supported language for process maps. We started by designing the Business Process Architecture Meta-Model (BPAM) for describing business process architectures as part of enterprise architectures [10]. Following [11], having a meta-model specification is a requirement for the definition of the abstract syntax of a modelling language. In our current work, we are designing a set of modelling languages for the BPAM. In our search, we came across the Signavio ${ }^{1}$ modelling platform for BPM. An interesting feature of Signavio is that it supports, apart from BPMN, also ArchiMate, which is the de facto standard EA modelling language. In Signavio, a Business Process element in an ArchiMate model can be linked to the BPMN diagram that models the process represented by this Business Process element.

The ability to link enterprise architecture models (in ArchiMate) with business process models (in BPMN) makes Signavio an interesting case for our research. Therefore, in this paper, we address the research question How to map BPAM onto ArchiMate such that Signavio can be used as a modelling platform for business process architecture? To investigate this research question, we designed a mapping of BPAM onto the ArchiMate meta-model such that process maps can be developed in Signavio.

The paper proceeds as follows: Section 2 provide background information on the integration of BPM and EA as intended by Signavio and on BPAM. Section 3 then presents our construct mapping. Section 4 concludes the paper and outlines future research.

1 https://www.signavio.com 


\section{Background}

\subsection{Integrating BPM and EA using Signavio}

In academic research, BPM and EA have developed as distinct disciplines with little interaction despite that business process is a key concept in both. Practitioners have, however, felt the need to connect the two fields [12]. For instance, Signavio (the company) has teamed up with Cisco Systems to evolve Signavio (the tool) into a common platform for BPM and EA management. With a combined tool that supports EA modelling with ArchiMate and business process modelling with BPMN, the process landscape can be integrated into the enterprise architecture [13]. The Signavio modelling platform also supports value chain modelling, similar - but not identical - to process landscape modelling as in [1]. Figure 1 shows a screenshot of how elements in a value chain diagram can be linked to BPMN process diagrams. Similar links can be created from within an ArchiMate model.

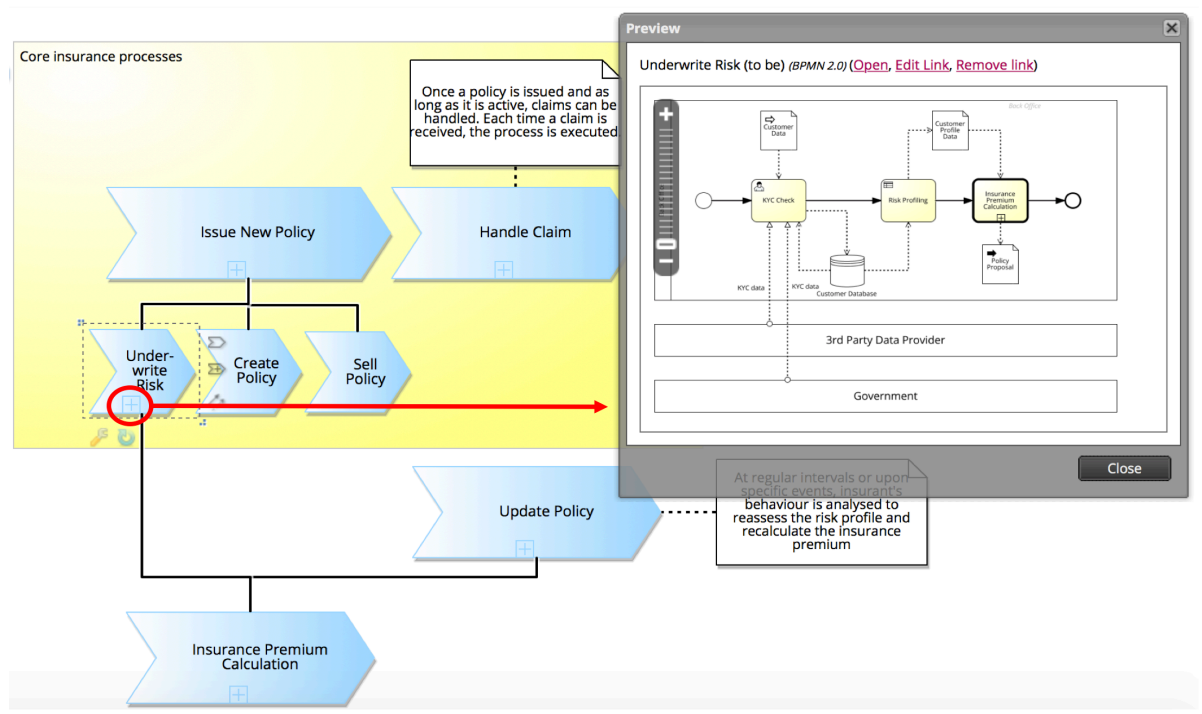

Fig. 1. Signavio screenshot of a value chain diagram with a link to a BPMN process diagram

It seems that the Signavio platform provides the functionality that would be required to describe business process architectures (in ArchiMate or using the tool's native value chain modelling notation) and to link business process architecture elements to BPMN process diagrams that detail the functional, control flow, data and resource aspects of business processes. Knowledge of how to develop process maps (e.g., guidelines, modelling patterns, consistency checking mechanisms) is, however, lacking. By offering a meta-model to represent business process architecture and mapping this meta-model onto ArchiMate, we provide a starting point of a method for developing process maps in Signavio and linking them with business process models. 


\subsection{Business Process Architecture Meta-Model}

The design of BPAM (Figure 2) was based on a literature review and concept mapping study, where we disentangled the concepts of business process architecture and process map (i.e., a description of (a view of) the business process architecture) [14]. Unlike the work of Malinova [9], BPAM is framed as a meta-model for and complies with the ISO/IEC/IEEE 42010 standard for architecture description, hereby transcending the BPM view of business process architecture as a management tool for large collections of business processes. Furthermore, BPAM includes a placeholder for enterprise architecture elements, allowing them to be related to business process architecture elements in process maps. As such, process maps can be integrated into enterprise architecture models, facilitating EA management techniques like strategic alignment analysis.

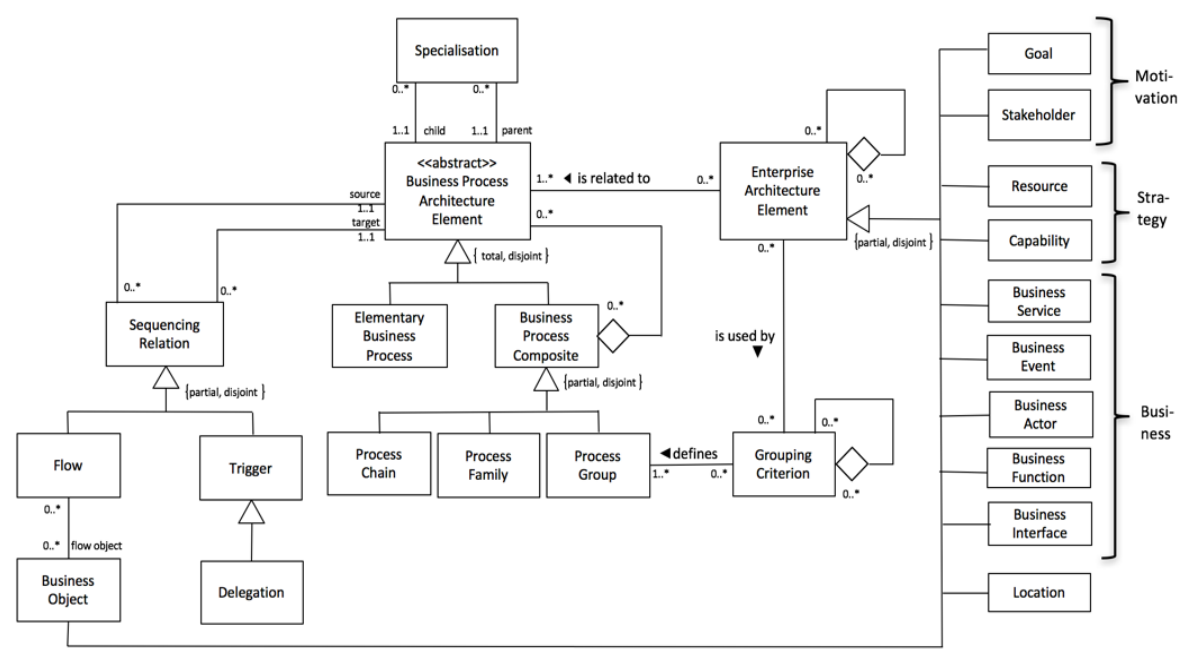

Fig. 2. Business Process Architecture Meta-Model [10]

Note that the multiplicity constraints in the meta-model have been relaxed to allow for multiple views of the business process architecture. For instance, one process map for a particular stakeholder/purpose might show a business process as elementary, while another process map for another stakeholder/purpose might show the same business process as composite. Likewise, though a flow is defined by a flow object, it is not required to show this object in the process map. Similarly, for process groups it is not required that the defining grouping criteria are shown in the process map.

Table 1 provides definitions of the BPAM elements. For more details, we refer to [10]. 
Table 1. Definition of BPAM elements (from [10])

\begin{tabular}{|l|l|}
\hline BPAM element & Definition \\
\hline $\begin{array}{l}\text { Elementary Business } \\
\text { Process }\end{array}$ & An atomic ${ }^{2}$ BPA element \\
\hline $\begin{array}{l}\text { Business Process } \\
\text { Composite }\end{array}$ & A BPA element that is not an elementary business process. \\
\hline Sequencing Relation & $\begin{array}{l}\text { A relationship between a source BPA element and a target BPA el- } \\
\text { ement implying a temporal ordering of source and target. }\end{array}$ \\
\hline Flow & $\begin{array}{l}\text { A sequencing relation in which a business object flows from source } \\
\text { to target. }\end{array}$ \\
\hline Business Object & $\begin{array}{l}\text { An object that flows between BPA elements (e.g., information, } \\
\text { physical items, persons). }\end{array}$ \\
\hline Trigger & $\begin{array}{l}\text { A sequencing relation in which the source instantiates and starts the } \\
\text { target. }\end{array}$ \\
\hline Delegation & $\begin{array}{l}\text { A trigger relation in which the source is dependent on the outcome } \\
\text { of the target. }\end{array}$ \\
\hline Process Chain & $\begin{array}{l}\text { An aggregate of BPA elements that are related through sequencing } \\
\text { relations. }\end{array}$ \\
\hline Specialization & $\begin{array}{l}\text { A relationship between a child element and a parent element imply- } \\
\text { ing that the child specializes the parent. }\end{array}$ \\
\hline Process Family & $\begin{array}{l}\text { An aggregate of BPA elements that are related through specializa- } \\
\text { tion relations where the parent assumes the role of standard process } \\
\text { and the children are variants of this standard process. }\end{array}$ \\
\hline Grouping Criterion & $\begin{array}{l}\text { A property that defines a process group (e.g., the process owner is } \\
\text { the CIO, the process category is core processes). }\end{array}$ \\
\hline Process Group & An aggregate of BPA elements defined by grouping criteria. \\
\hline $\begin{array}{l}\text { Enterprise Architec- } \\
\text { ture Element }\end{array}$ & $\begin{array}{l}\text { An element that is part of the enterprise architecture and that is re- } \\
\text { lated to a BPA element (e.g., a capability realized by a BPA element, } \\
\text { a business actor participating in a BPA element). }\end{array}$ \\
\hline
\end{tabular}

\section{Representing Process Maps with ArchiMate}

To represent process maps as instantiations of BPAM with ArchiMate in Signavio, the meta-model concepts were mapped onto ArchiMate concepts. Table 2 presents the results of this mapping.

Table 2. Construct mapping BPAM onto ArchiMate and notation in Signavio

\begin{tabular}{|l|l|c|}
\hline BPAM concept & ArchiMate concept & $\begin{array}{l}\text { ArchiMate Notation } \\
\text { (in Signavio) }\end{array}$ \\
\hline $\begin{array}{l}\text { Elementary } \\
\text { Business Process }\end{array}$ & Business Process \\
\hline
\end{tabular}

2 Atomic means that the internal structure and operation of the business process is hidden. The process map thus provides a black-box view of elementary business processes [15].

3 Following [15], the standard process represents the process family. 


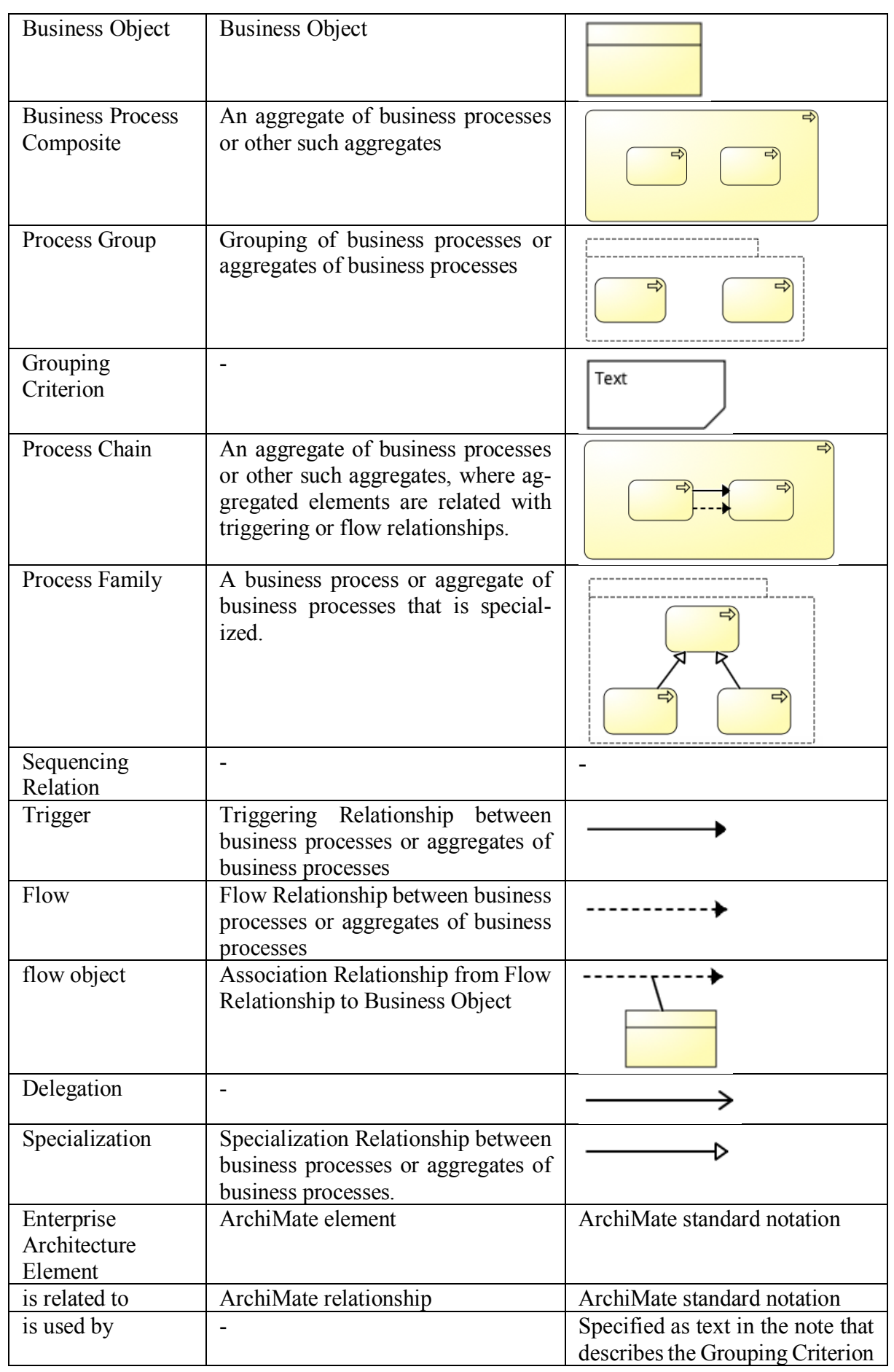


When designing the mapping, compromises were made as Signavio strictly adheres to standard ArchiMate and does not support language extension mechanisms. Modelling a BPAM Business Process Composite (or its BPAM Process Chain specialization) as an aggregate of business processes or other such aggregates is clear as long as the aggregated elements are explicitly shown in the process map, which is not required given the high level of abstraction allowed in process maps [10]. If the aggregated elements are not shown, then the mapping is not injective (i.e., the ArchiMate Business Process symbol may represent a BPAM Elementary Business Process or a BPAM Business Process Composite). The same problem holds for BPAM Process Groups and BPAM Process Families, although here the association with a text notation (describing the grouping criterion), even if not mandatory, helps distinguishing between these types of business process composite.

The construct mapping is incomplete for the BPAM Grouping Criterion element and is used by relationship, although both can be represented using text annotations. There is no such solution for the BPAM Sequencing Relation, which is only problematic when BPAM elements are sequenced differently than with trigger, delegation or flow relationships - a case which is rare in practice [10]. The mapping of the BPAM Delegation Relation onto the ArchiMate Serving relationship is unconventional as Serving is not a dynamic relationship (like Triggering and Flow). Therefore we propose to use the ArchiMate symbol for Serving to represent BPAM Delegation in Signavio, while semantically considering it as a Sequencing relation. The source of the Delegation relation is the BPAM element that delegates, while the target is the BPAM element that is delegated to. Visually, however, the source is located at the arrowhead of the Serves relationship, while the target is located at the base of the arrow.

\section{Conclusion}

The mapping of BPAM onto ArchiMate allows developing process maps in Signavio that are part of the enterprise architecture model of an organization. Signavio allows linking such process maps to process diagrams that detail the processes. Process maps representing (views of) the business process architecture as part of the enterprise architecture can be useful for strategic alignment analysis of an organization's business processes. We see strategic alignment as the fit for purpose of an organization's processes, which is a business process quality dimension that has received little attention in BPM research, despite the recognition of strategic alignment as a key success factor for BPM [1]. This is just one example of a benefit of better integrating the BPM and EA disciplines. Our research on BPAM contributes to the integration of both disciplines.

Further research is required. The linking of enterprise architecture models and business process models in Signavio needs further investigation. For instance, we are developing a consistency checking mechanism for process maps (in ArchiMate) and process diagrams (in BPMN). Further research is also needed to establish a bijective mapping (e.g., by using ArchiMate extension mechanisms). The mapping presented in this paper, specifically aimed at being able to develop process maps in Signavio, results in one of several alternative notations for BPAM we are currently investigating. 


\section{Acknowledgements}

This work is supported by the projects BIZDEVOPS-Global (ref. RTI2018-098309-BC31), funded by the Spanish Ministry of Economy, Industry and Competition (MINECO) \& FEDER and G3Soft (Engineering of Models for Governance and Management of Global Software Development) funded by "Consejería de Educación, Cultura y Deportes de la Dirección General de Universidades, Investigación e Innovación de la JCCM" of Spain.

\section{References}

1. Dumas, M., La Rosa, M., Mendling, J., Reijers, H.A.: Fundamentals of Business Process Management. 2nd edn. Springer, Berlin (2018).

2. Bøegh, J.: A new standard for quality requirements. IEEE Software, March/April 2008, 57$63(2008)$.

3. Henderson, J.C., Venkatraman, N.: Strategic alignment: Leveraging information technology for transforming organizations. IBM Systems Journal 36(2\&3), 472-484 (1999).

4. Delgado, A., Weber, B., Ruiz, F., Garcia-Rodríguez de Guzmán, I., Piattini, M.: An integrated approach based on execution measures for the continuous improvement of business processes realized by services. Information and Software Technology 56, 134-162 (2014).

5. Moreno-Montes de Oca, I., Snoeck, M., Reijers, H.A., Rodríguez-Morffi, A.: A systematic literature review of studies on business process modelling quality. Information and Software Technology 58, 187-205 (2015).

6. Sánchez-González, L., García, F., Ruiz, F., Piattini, M.: A case study about the improvement of business process models driven by indicators. Software \& Systems Modeling 16(3), 759788 (2017).

7. Roelens, B., Steenacker, W., Poels, G.: Realizing strategic fit within the business architecture: The design of a process-goal alignment modelling and analysis technique. Software \& Systems Modeling 18(1), 631-662 (2019).

8. Heinrich, B., Henneberger, M., Leist, S., Zellner, G.: The process map as an instrument to standardize processes: Design and application at a financial service provider. Information Systems and E-Business Management 7, 81-102 (2009).

9. Malinova, M.: A language for designing process maps: Abstract syntax, semantics and concrete syntax. PhD dissertation, Vienna University of Economics and Business (2016).

10. Poels, G., García, F., Ruiz, F., Piattini, M.: Architecting Business Process Maps. Submitted for publication (2019).

11. Guizzardi, G.: Ontological Foundations for Structural Conceptual Models. PhD dissertation, University of Twente (2005).

12. von Rosing, M., Hove, M., Subbarao, R.R., Preston, T.W.: Getting Business Transformation right: Combining BPM and EA (2012).

13. Lakhegyi, P., Decker, G., Klauberg, K.: The integration of EAM and BPA (2013).

14. Poels, G., García, F., Ruiz, F., Piattini, M.: Conceptualizing Business Process Maps: Technical report as a complement to Architecting Business Process Maps (2018). https://arxiv.org/abs/1812.05395.

15. Van Nuffel, D., De Backer, M.: Multi-abstraction layered business process modelling. Computers in Industry 63(2), 131-147 (2012). 